REVISTA BRASILEIRA dE ANÁlise do COMPORTAMENTO / BRAZILIAN JOURNAL OF BEHAVIOR ANALYSIS, 2018, VOL. 14, N 2, $191-198$.

\title{
THE (NON) DEFINITION OF AVERSIVE CONTROL IN BEHAVIOR ANALYSIS
}

\author{
MARIA HELENA LEITE HUNZIKER - ORCID 0000-0003-0030-375K \\ UNIVERSIDADE DE SÃo PAULO, BRASIL
}

\section{RESUMO}

A literatura de Análise de Comportamento descreve dois tipos de controle: aversivo e positivo. Uma revisão de publicações especializadas revelou uma definição objetiva de controle por reforço positivo, mas nenhuma definição de controle aversivo. Neste artigo, discutimos o significado científico dos termos "controle" e "aversivo" do ponto de vista da Análise do Comportamento. Nós nos concentramos nas probabilidades relacionais entre respostas e estímulos que ocorrem durante a interação contínua entre organismos e o ambiente. Supõe-se que o termo "controle" significa que um evento (o controlado) é alterado pela ocorrência de outro evento (o controlador). A aversividade do controle é analisada em função das "operações" (adição e subtração do estímulo), seus "efeitos" (aumento ou diminuição da probabilidade de resposta) e "natureza do estímulo" envolvido (aversivo ou apetitivo). Concluímos que uma análise de processos, operações e de natureza do estímulo foi incapaz de identificar um fator comum a todas as relações comportamentais definidas como aversivas. Consideramos que, sem critérios claros para classificar um controle como aversivo, seria mais parcimonioso falar sobre o controle comportamental sem usar a dicotomia aversivo/positivo. Entretanto, se esta dicotomia for mantida, o desenvolvimento de uma análise objetiva de respostas eliciadas (emocionais) pode ser uma maneira de caracterizar a referida distinção.

Palavras-chave: controle; controle aversivo; controle positivo; Análise do Comportamento; questões conceituais.

\begin{abstract}
The Behavior Analysis literature describes two types of control: aversive and positive. A review of specialized publications revealed an objective definition of control through positive reinforcement, but no definition of aversive control. In this paper, we discuss the scientific meaning of the terms "control" and "aversive" from the viewpoint of behavior analysis. We focus on the relational probabilities between responses and stimuli that occur during the continuous interaction between organisms and the environment. The term "control" is assumed to mean that one event (the controlled one) is changed by the occurrence of another event (the controller). The aversiveness of the control is analyzed as a function of "operations" (addition and subtraction of the stimulus), their "effects" (the increase or decrease of the response probability) and the "nature of the stimulus" involved (aversive or appetitive). We conclude that an analysis of processes, operations, and the nature of the stimulus was unable to identify a factor common to all the behavioral relations defined as aversive. We consider that without clear criteria for classifying a control as aversive, it would be more parsimonious to talk about behavioral control without using the aversive/positive dichotomy. However, if this dichotomy is maintained, the development of an objective analysis of elicited (emotional) responses may offer a way to characterize the aversive/positive distinction.
\end{abstract}

Key words: control; aversive control; positive control; behavior analysis; conceptual questions.

\footnotetext{
This text is a revised version of the paper Hunziker, M. H. L. (2011). Afinal, o que é controle aversivo? Acta Comportamentalia, 19, 9-19. The author received research support from CNPq (process number 304120/2016-2). Email: hunziker@usp.br
}

DOI. 10.18542/rebac.v14i2.7538 
The behavior analysis literature describes two types of control: aversive and positive. Based on Hineline's (1984) conclusion that aversive control is not a specific type of control, it would be more parsimonious to talk about behavioral control without using this dichotomy. However, this dichotomy has been present since the earliest experiments and remains in use today, although variations in the terminology exist (Mayer \& Gongora, 2011). This persistence of the aversive/positive dichotomy may be an indication that it contributes to the understanding of the central phenomenon, namely, the behavior. If this is the case, clear definitions of the two types of control are required. A review of the specialized literature revealed that although there is an objective definition of control by positive reinforcement, no such definition of aversive control exists. Rather, there is only a listing of operant and respondent relations that are classified as aversive (see Catania, 1998).

The fact that aversive control has been described by listing certain behavioral contingencies, while the rationale for such a grouping of these contingencies is that they are aversive, indicates a circular analysis. Conceptual inaccuracies and circular analysis are not welcome in science. Considering that behavioral analysis is a science that advocates conceptual precision, the present text aims to identify clear criteria for classifying aversive control that avoid the circular analysis mentioned above. We will try to identify these criteria based on the analysis of two terms: "control" and "aversive".

\section{WHAT IS CONTROL?}

In behavior analysis, the term "control" is common. For example, the prediction and control of behavior are considered the goals of this science (Skinner, 1953); furthermore, one of the foundations of operant analysis is the control by consequences (Skinner, 1974), and stimulus control and aversive control are systematically investigated areas of study (Catania, 1998).

Although "control" is a technical term in behavior analysis, it is also used in the common vernacular to convey different meanings. Examples include quality control (the inspection of activities or products to ensure that they do not deviate from the pre-established norms), sound control (the movement of buttons or keys on sound equipment to adjust the characteristics of sound), flight control (a technical necessity for safe airplane flights), etc.. In terms of social interactions, "control" is often synonymous with oppression and standardization. Especially in cultures in which people have lived (or live) under authoritarian political regimes, the term control is synonymous with limiting individual freedom or reducing differences of opinions and lifestyles. In other words, in nonscientific environments, "control" is often associated with the notion of domination and imposition. Thus, a negative connotation (tyrannical, arbitrary, authoritarian role) is associated with the controlling person.
Considering that scientists are influenced by their culture, it is not surprising that the use of the term control in the behavioral sciences foments rejection because of the implications from its lay use. In this sense, a replacement for the scientific use of this term could avoid interference from the lay meaning. However, we know how difficult it is to change a long-used technical term: if such an attempt is made, the change will not be immediate. Therefore, until "control" is replaced (if it is replaced) with another technical term, we must distinguish it from its lay meaning and clearly establish its technical/scientific significance.

Even some scientific uses of "control" are of no interest to the analysis proposed here. Methodologically, we speak of experimental conditions (involving the manipulation of an independent variable while the others are kept constant/controlled) and control conditions (one in which the independent variable under study is not present). However, these are not the scientific uses of the term that we want to analyze. The meaning that is relevant to the analysis proposed here is inherent to the logic of functional relations: if $\mathrm{B}$ is a function of $\mathrm{A}$, then $\mathrm{A}$ controls $\mathrm{B}$. Given that the study of functional relations is probabilistic, this control relationship between events must be considered in the same way. Consequently, in the remainder of this paper, "control" will mean nothing more than the fact that one event's probability of occurrence ${ }^{1}$ is altered by another event.

For control to be established or identified, one must consider the difference between two relational probabilities involving both the occurrence and the absence of the supposedly controlling event (Catania, 1972). For example, if the probability of the occurrence of $\mathrm{B}$ is always high after the occurrence of $\mathrm{A}(\mathrm{p}(\mathrm{B} / \mathrm{A})=1.0)$ and is null in the absence of $\mathrm{A}(\mathrm{p}(\mathrm{B} / \mathrm{nA})=0.0)$, we can say that this difference between the probabilities indicates that A controls B. In the behavior analyst's laboratory, if the probability of a food pellet presented in the experimental box is 1.0 after a rat presses a bar and is 0.0 in its the absence of this action (i.e., a continuous reinforcement program), we can say that, by definition, the press response to the bar controls the presentation of the food pellet. In daily life, if pressing the " $t$ " key on the computer keyboard makes the letter " $t$ " appear, we can say that we have control over the appearance of this letter on the screen. However, when a virus infects our computer and phrases begin to appear on the screen independent of our action, we have a typical situation in which our control over the writing displayed on the computer screen is reduced (or abolished).

Quantification of the degree of control depends on the magnitude of the difference between the two examined probabilities, which can vary from 0.0 to 1.0. Thus, the degree of control is greater as the difference in probability

\footnotetext{
${ }^{1}$ The same analysis can be applied to change the probability of other dimensions of the response, such as strength, duration, topography, etc.
} 
between the two terms of the equation increases. In the example of the rat exposed to continuous reinforcement, this difference was the maximum possible (1.0), which indicates that the press response to the bar has full control over the presentation of the food pellet. If reinforcement was available at a variable ratio two (VR 2), each press of the bar would have an intermediate level of control over food presentation $(\mathrm{p}=0.5)$. However, if the probability of the food being presented was the same after a bar press or no press, then we would have a condition in which the subject's response would have no control over the food presentation, i.e., presses to the bar and food presentation would be independent events.

Therefore, following this definition, we must consider that operant contingencies necessarily involve bidirectional control relations: (a) the control relation established by the subject over his environment and (b) the control relation established by the environment over the organism. ${ }^{2}$ From this perspective, even though a stimulus $(\mathrm{S})$, which is not contingent on a response (R), interferes with the probability of future responses, conceptually speaking, this relation does not characterize control by its consequences. In fact, one can only speak about consequences in the R-S relation when there is a dependent relation between the events, i.e., when the probability of $S$ is modified by $\mathrm{R}$. If this relation is only temporal ( $\mathrm{R}$ does not change the probability of S), it does not involve consequence but rather contiguity. The analysis of the relevance of contingency and/or contiguity in determining behavior, though intriguing (Bloomfield, 1972; White, 2009), is not the objective of the present text. Therefore, we will focus only on R-S relations that involve control the way it has been defined here.

In addition, there are others relations in which control is characterized by the fact that $S$ changes the probability of the occurrence of $\mathrm{R}$, which follows it (S-R relation). In the same manner described above, this relation also involves an equation with two relational probabilities ( $\mathrm{p}(\mathrm{R} / \mathrm{S})$ and $\mathrm{p}(\mathrm{R} / \mathrm{nS})$ ): when the two probabilities differ, we have a relation in which $S$ controls $R$, and the degree of control is directly proportional to the magnitude of this difference. Whenever the two probabilities are equal, we have a condition in which control is not established at the levels analyzed here. When the difference between these probabilities is high (1.0 or nearly 1.0$)$, we have a relation called elicitation (respondent process). When the difference is less than 1.0, the process is called induction (Baum, 2005); in relations of three or more terms with the structure S-R-S and a difference of less than 1.0, this process is called stimulus control (Catania, 1972).

\footnotetext{
${ }^{2}$ By response and stimulus, we mean the response class and stimulus class, respectively (Catania, 1998).
}

In respondent relations, there is still the pairing of stimuli (S-S relations) that does not involve control because the first stimulus (S1) does not change the probability of the second stimulus (S2), even though it precedes it. Between these stimuli, there is only temporal contiguity. However, the product of this pairing is the establishment of a new behavior control relation: if $\mathrm{S} 1$ does not initially elicit $\mathrm{R}$ (which is controlled only by S2), through the pairing S1-S2, $\mathrm{S} 1$ will begin to elicit $\mathrm{R}$, i.e., it will change the probability that $\mathrm{R}$ will occur. In other words, $\mathrm{S} 1$ will begin to control $\mathrm{R}$ as a conditioned stimulus (Catania, 1998).

The bidirectionality inherent in the technical/scientific concept of "control" as adopted by behavior analysis abolishes, as a matter of principle, the authoritarianism suggested by the lay usage of the term. Given that control is inherently bidirectional, there is no isolated power in any part of the behavioral relation: if the organism can change the environment and be modified by it, the analysis involves a condition in which the organism and environment are mutually changed. Metaphorically, this process is analogous to a spiral tracing circles that never return to the same point of origin: with each turn completed by the spiral, it will pass (but not retrace) the point visited on the previous turn because the two parts of the relation were modified during that turn.

In the respondent interactions, the bidirectionality of control is not as explicit because the central action is not of the organism towards the environment but of the environment towards the organism. If operant and respondent interactions were independent from each other, this would be a problem for the analysis of the bidirectionality of control. However, the operant/respondent interaction is a constant, and the conventional division between operant and respondent is only didactic, to facilitate the identification of some of the existing controls in the behavior under study (Donahoe \& Palmer, 1994). Just as one cannot neglect the fact that, in the operant interactions, the consequent $\mathrm{S}$ must necessarily produce (elicit) some change in the organism (otherwise it would not be a stimulus), in the respondent interactions, it is expected that the elicited $\mathrm{R}$ will in some way contribute to the change in the probability of the organism's actions towards the environment, either as part of a behavioral chain or by fulfilling the role of establishing operation (Michael, 1975). By principle, given that behavior is a process of continuous interaction, there is no relation that is an end in and of itself. Therefore, the bidirectionality of control is assumed to be an inherent part of the behavioral process. This concept of control is the antithesis of the establishment of behavioral stereotypy; control is necessarily dynamic and involves interaction between parts, producing constant and cumulative renewal. This nature of control establishes the enormous complexity of the behavior of organisms and their inevitable individuality.

In summary, in the sense provided here, "control" is equally applicable to operant and respondent relations. In 
nature, these relations are continuous and involve endless links. This suggests that in the study of these relations, they can be infinitely combined and amplified with regard to their components. Consequently, we can identify the changes in the functions of the stimulus, i.e., its ability to control the occurrence of different responses, either those that follow it or those that precede it. In this way, we can investigate how seemingly simple operations and processes, because they are continuous and cumulative, can compose a complex network of behavior control (Donahoe \& Palmer, 1994).

\section{WHAT IS AVERSIVE?}

Given the functional definition of "control," it remains to be seen what makes it aversive. The textbooks on behavior analysis do not define what aversive control is; they only classify the behavior relations that have that denomination. Although this classification has historically occurred in different ways (see Gongora, Mayer, \& Mota, 2009 , on changes in the terminology used in the area), the current more significant classification proposes that two factors establish the criteria for classifying the four basic operant relations (Table 1): the first is the operation, i.e., whether the stimulus is added (+) or removed (-) as a consequence of the response. The second factor is related to the behavioral effect, i.e., whether the response is strengthened (i.e., has an increased probability of future occurrence) or weakened (i.e., has a decreased probability of future occurrence) as a function of the operation. The strengthening of the response in terms of its consequences is called reinforcement, and its weakening is called punishment. The combination of the two factors (operation and effect) establishes the four basic operant relations: positive reinforcement (+ operation, increasing effect), negative reinforcement (- operation, increasing effect), positive punishment (+ operation, decreasing effect), and negative punishment (- operation, decreasing effect). With the exception of positive reinforcement, all other operant relations are considered to involve aversive control (Baum, 2005; Catania, 1998).

In addition, the dual nature of the stimuli involved in these behavioral relations - aversive or appetitive - is highlighted in Table 1. This designation of the stimulus is essentially functional, i.e., it depends on the effect of the stimulus within a relation of which it is part. The stimulus is deemed aversive if its contingent removal due to a response has the effect of increasing the probability of future occurrences of that response or if its presentation contingent on a response reduces the future probability of the response occurring (inverse relations define the stimulus as appetitive). Therefore, stimuli that are part of the behavioral relations called positive punishment and negative reinforcement are classified as aversive, and stimuli that are part of positive reinforcement and negative punishment contingencies are classified as appetitive (Baum, 2005; Catania, 1998).
However, the mere designation of these relations as aversive does not establish the common factor that causes them to be grouped in that way. If we say that a punishment relation involves aversive control and that it is aversive control because it is a punishment relation, we are engaging in undesirable circular reasoning. The joint analysis of operation and effect, which has been created to avoid this circularity is sufficient to characterize each relationship individually but not to justify its grouping. In the case of positive reinforcement considered in isolation, there is nothing to question. However, when we group three different behavioral relations under the common denomination of aversive control, we have to identify the common factor that justifies this grouping. What common element allows us to designate a relation as aversive?

Table 1

Schematic representation of the four basic operant contingencies. The $R-S$ relations that are currently considered to involve aversive control are shaded.

\begin{tabular}{|l|c|c|}
\hline OPERATION & $\begin{array}{r}\text { R-S } \\
(+)\end{array}$ & $\begin{array}{r}\text { R-S } \\
(-)\end{array}$ \\
\hline 5 PFFECT $(\mathrm{R})$ & $\begin{array}{c}\text { REINFORCEMENT }+ \\
\text { (S appetitive) }\end{array}$ & $\begin{array}{c}\text { REINFORCEMENT - } \\
\text { (S aversive) }\end{array}$ \\
\hline$\square \mathrm{P}(\mathrm{R})$ & $\begin{array}{c}\text { PUNISHMENT + } \\
\text { (S aversive) }\end{array}$ & $\begin{array}{c}\text { PUNISHMENT - } \\
\text { (S appetitive) }\end{array}$ \\
\hline
\end{tabular}

Could the behavioral effect be this factor? Analyzing Table 1, we must conclude that this is not a reliable criterion because it does not cover all relations that are considered aversive. For example, if the characteristic effect of aversive relations is the weakening of the response, only the two types of punishment would be included; this would leave out negative reinforcement, which is typically considered an aversive relation. If the characteristic effect of aversive relations is the strengthening of the response, the two punishments would be excluded and the two reinforcements would be included; this would result in the inclusion of positive reinforcement, which is actually the only non-aversive relation in this classification. So, we can conclude that the effect of a behavioral interaction (weakening or strengthening the response) is not the factor that characterizes aversive control.

If so, can the aversive control be characterized by the established operation? The answer is no because none of the operations are common to the three aversive operant relations: the removal of the stimulus contingent on the response occurs in the cases of negative reinforcement and punishment, but in positive punishment, the operation is the addition of a stimulus. Therefore, the use of the operation as 
the factor that classifies the behavioral relation as aversive is also discarded. Finally, if there is no operation or effect common to all aversive operant relations, does this classification depend on the "nature of the stimulus" (aversive) that is part of it? Again, this is not a satisfactory alternative either because it omits negative punishment, which involves an appetitive stimulus, leaving this process out of the classification as aversive.

This analysis leads to the conclusion that there is no objective criterion for a given operant relation to be classified as aversive. The weakening of the response could be adopted as a sufficient criterion if the proposal by Michael (1975) to abolish the operations of addition and removal of the consequent stimulus as part of the classification of operants were to be accepted in the literature. According to that author, if a consequence relation produces an increase in the future probability of the response, it characterizes a reinforcement relation; if it produces a decrease, it characterizes a punishment. According to Michael, defining these relations as positive or negative is not necessary for the proper analysis of the behavior.

Despite its apparent theoretical/conceptual logic, Michael's (1975) proposal did not generate changes in the way behavior analysts classify operant relations, as Baron and Galizio (2005) indicate. This low adherence to Michael's proposal seems to indicate that it did not solve the problems associated with conventional classification. A thought-provoking debate on this topic has been conducted by specialists in a series of articles published in The Behavior Analyst journal (Baron \& Galizio, 2006a, 2006b; Chase, 2006; Iwata, 2006; Lattal \& Lattal, 2006; Marr, 2006; Michael, 2006; Nakajima, 2006, Sidman, 2006; Staats, 2006). The result of this large series of papers showed that there was no consensus among the authors regarding the suitability of Michael's proposal (1975). Interestingly, even many of those who theoretically agreed with him have stated that, in practice (in teaching or research), they continue to use the conventional quadruple classification that considers operation (in addition to effect) a criterion for the classification of operant relations.

The problem of a lack of objective criteria for classifying control as aversive is even more pronounced in the study of respondent relations. For example, what defines the relations that control elicited aggression (Azrin, Hutchinson, \& Sallery, 1964) or conditional suppression (Estes \& Skinner, 1941) as aversive? Additionally, given the variables that allow such classifications to be specified, are there any that are common to both, thus justifying the grouping of such distinct relations under the same designation? As far as we can see, neither of these questions has been answered satisfactorily. The behavioral effect does not seem to be the determinant of an aversive characterization: in aggression studies, the effect involves an increase in a topographically defined response (aggression), whereas in conditioned suppression studies, it refers to a reduction in the probability of the occurrence of a functionally defined response (maintained by positive reinforcement). Thus, there is apparently no way to support the use of the behavioral effect as a common criterion for these respondent relations, which are also called aversive. Another alternative would be to consider the nature of the elicitor stimulus as a criterion for defining the aversiveness of the control. However, in behavior analysis, there is usually no direct functional classification of stimulus aversiveness in the respondent relations: the aversive nature of the stimulus (i.e., stimuli that produce escape/avoidance or positive punishment) is usually inferred from operant studies. ${ }^{3}$ In this context, electric shock, which is used both in elicited aggression and conditioned suppression studies, is always considered an aversive stimulus even if escape, avoidance, or positive punishment are not directly tested.

When we consider that aversive functions are not directly tested in the respondent studies, we find another problem: the attribution of the nature of the stimulus without a demonstration of its functionality. The a priori attribution of the function of the stimulus damages the conceptual accuracy that the field proposes for this classification. Finally, physically similar stimuli (i.e., those of the same duration, intensity, waveform, etc.) can be functionally aversive when they are part of one contingency but not when they are part of another. For example, Perone (2003) compared studies in which electric shocks with an intensity below 1.0 mA functioned as aversive stimuli in a punishment contingency but not in an avoidance contingency. If such differences exist among operant relations, what can be said about the differences between operant and respondent relations, which already naturally differ in other respects? The desirable thing would be for the study of respondent relations to apply the same rigor as operant studies, establishing independent criteria that allow the objective classification of a stimulus as aversive. This is a task that is yet to be pursued in this field.

In the absence of more general criteria, an alternative adopted by some researchers has been to quantify some responses that are elicited by certain stimuli to allow their classification as aversive elicitors. For example, the frequency and intensity of vocalizations and abrupt body movements (jumps, races, etc.) are responses often elicited by electric shock depending on its intensity. In this sense, some authors use these responses to define the minimum intensity of shocks that would allow them to be classified as aversive (Santos \& Hunziker, 2010). Likewise, the paw-

\footnotetext{
${ }^{3}$ Other biological sciences use some physiological measurements as direct indicators of the aversiveness (or "stressful" nature) of a stimulus, such as the release of glucocorticoids as a product of activation of the hypothalamic-pituitary-adrenal (HPA) axis (Palermo-Neto, 2006). However, these measurements are not generally adopted as aversive criteria in studies related to behavior analysis.
} 
licking response has been considered to be an indicator of aversiveness in studies on pain elicited by applications of high temperature to the skin of rats tested on a hot plate (Hunziker, 1992). However, although these criteria make the classification of the stimulus (electric shock or temperature) as aversive more objective, they have the disadvantage of being specific to the manipulated stimuli and the species subjected to them: rats do not lick their paws when they receive shocks through the floor, nor do they vocalize when placed on a heated surface at $50^{\circ} \mathrm{C}$. Similarly, the same electric shock intensity may be aversive to a rat, but not to a dog. Therefore, there is not a general way to objectively classify the eliciting stimulus as aversive.

The previous analysis can be extended to other aversive behavioral interactions. For example, experiments have demonstrated that operant extinction makes aggressive responses more likely to occur (Azrin, Hutchinson, \& Hake, 1966). This means that even if discontinuity of reinforcement is not an operation typical of aversive relations, it exerts the same function (eliciting aggression) that has already been demonstrated by electric shocks, i.e., it is also aversive. Similarly, it is not typical of aversive control that a stimulus associated with a lower probability of positive reinforcement in multiple schemes can acquire a punitive function (Jwaideh \& Mulvaney, 1976), or a fixed ratio schedule for positive reinforcement can induces responses that produces time-out period (that suppress the positive reinforcement), which are interpreted as escape (Azrin, 1961). These (and other) experimental data suggest that positive reinforcement schemes may also involve aversive contingencies (Perone, 2003), which indicates the need to review the aversive/positive reinforcement dichotomy in light of experimental studies.

In summary, we can conclude that the analysis of the processes, operations and nature of the stimulus was unable to identify a factor common to all of the behavioral relations designated as aversive. Nonetheless, the distinction between aversive control and positive reinforcement has been maintained; what other type of variable has sustained it?

\section{POSSIBLE ALTERNATIVES}

The aversive/non-aversive dichotomy is analogous to the common-sense distinctions between good/evil, pleasant/unpleasant, and other equivalent antagonistic relations. For the layperson, the relations classified as aversive have as a common factor their unpleasantness or undesirableness. In nontechnical language, it is considered pleasant to gain something that one likes, just as it is unpleasant to lose something one likes. It is unpleasant if something we do causes us suffering or discomfort or if we experience situations that bother us to the point of seeking ways to abolish or avoid them. Although a reference to feelings of discomfort or suffering is not a reliable parameter for the scientific analysis of behavior, it points to some private events, named through verbal community shaping
(Skinner, 1957), that are generally (but not always) compatible with the scientific classification of behavioral relations and stimuli designated as aversive.

Given the imprecision of subjectivity, the science of behavior has proposed to work only with objective functional relations to substantiate its concepts and analyses (Watson, 1913). Thus, the description of sensations (among other private events) has not been considered a reliable criterion for designating stimuli or the established functional relations as aversive. The lack of an objective criterion that justifies the grouping of aversive relations allows us to ask whether the scientific behavior of classifying aversive relations is informally controlled by the consideration of the private responses elicited under certain conditions, although such considerations are not formally performed. In other words, will behavior analysts use as the ultimate (albeit undeclared) criterion that the assumption of unpleasant sensations underlies the classification of a relation as aversive? As Michael (1975) mentioned, the terminology of positive reinforcement versus aversive control could be the behavior analysis community's way of referring to "good and bad things". If the criterion that has been used to justify the grouping of different relations under the designation of aversive control is the qualitative aspects of the private elicited responses (sensations), this criterion is not being formally considered in most of the behavior analysis literature. However, there are exceptions. For example, Staats (2006) highlighted the fact that the emotional response elicited by aversive relations is very different from that elicited by positive reinforcement. According to Staats, the absence of a distinction between such responses ignores an important aspect of behavior: given that private responses are part of the behavioral flow, they can alter the likelihood of other public responses occurring.

In agreement with Staats (2006), we consider that it may be indispensable to find ways to include in our analysis the private responses elicited by the stimuli that are constituents of the interactions of the organism with the environment. If we develop ways to study the world under the skin (Skinner, 1974), the analysis of elicited responses (referred to as emotional responses) may provide a more complete view of our object of study. To reach this goal, it will be essential to involve the neurosciences. The experimental discoveries of that field may help in this endeavor to make the measurement and manipulation of emotional responses objective (Donahoe \& Palmer, 1994).

We consider that the vast predominance of the study of operant analysis and positively reinforced relations is only one step in the construction of the science of behavior (Catania, 2008). Currently, respondent relations have been left in the background as if they were responsible only for "simple" reflexive behaviors. The extension of the study of respondent relations may account for some problems that seem to have no solution through purely operant logic, such as the classification and analysis of aversive control discussed here. In this sense, the unified 
reinforcement process proposed by Donahoe and Palmer (1994) seems to be a promising alternative for achieving greater operant and respondent integration in the study of behavior.

\section{DECLARATION OF CONFLICT OF INTEREST}

The authors declare that there is no conflict of interest regarding the publication of this article.

\section{COPYRIGHT}

This is an open article and may be freely reproduced, distributed, transmitted or modified by anyone provided it is used for non-commercial purposes. The work is made available under the Creative Commons 4.0 BY-NC license.

$$
\text { (cc) BY-NC }
$$

\section{REFERENCES}

Azrin, N. H. (1961). Timeout from positive reinforcement. Science, 81, 382-383. doi: 10.1126/science.133.3450.382

Azrin, N. H., Hutchinson, R. R., \& Hake, D. F. (1966). Extinction-induced aggression. Journal of the Experimental Analysis of Behavior, 9, 191-204. doi: 10.1901/jeab.1966.9-191

Azrin, N. H., Hutchinson, R. R., \& Sallery, R. D. (1964). Pain-aggression toward inanimate objects. Journal of the Experimental Analysis of Behavior, 7, 223-228. doi: 10.1901/jeab.1964.7-223

Baron, A., \& Galizio, M. (2005). Positive and negative reinforcement: Should the distinction be preserved? The Behavior Analyst, 28, 85-98. doi: 10.1007/bf03392107

Baron, A., \& Galizio, M. (2006a). The distinction between positive and negative reinforcement: Use with care. The Behavior Analyst, 29, 141-151. doi: 10.1007/bf03392127

Baron, A., \& Galizio, M. (2006b). Distinguishing between positive and negative reinforcement: Responses to Nakajima (2006) and Staats (2006). The Behavior Analyst, 29, 273-277. doi: 10.1007/bf03392137

Baum, W. M. (2005). Understanding behaviorism: Behavior, culture, and evolution (Revised Edition). Malden, MA: Blackwell.

Bloomfield, T. M. (1972). Reinforcement schedules: Contingency or contiguity? In R. M. Gilbert \& S. R. Millenson (Eds.), Reinforcement: Behavioral analysis (pp. 165-208). New York, NY: Guilford Press.

Catania, A. C. (1972). Elicitation, reinforcement and stimulus control. In R. Glaser (Ed.), The nature of reinforcement (pp. 196-220). New York, NY: Academic Press.
Catania, A. C. (1998). Learning (4th ed.). Upper Saddle River, NJ: Prentice-Hall.

Catania, A. C. (2008). The Journal of the Experimental Analysis of Behavior at zero, fifty, and one hundred. Journal of the Experimental Analysis of Behavior, 89, 111-118. doi: 10.1901/jeab.2008.89-111

Chase, P. N. (2006). Teaching the distinction between positive and negative reinforcement. The Behavior Analyst, 29, 113-115. doi: 10.1007/bf03392121

Donahoe, J. W. \& Palmer, D. C. (1994/2017). Learning and complex behavior. (Originally published Allyn \& Bacon. Boston, MA.) Third reprinting: Richmond, MA: Ledgetop Publishing. http://lcb-online.org/

Estes, W. K., \& Skinner, B. F. (1941). Some quantitative properties of anxiety. Journal of Experimental Psychology, 29, 390-400. doi: 10.1037/h0062283

Gongora, M. A. N., Mayer, P. C. M., \& Mota, C. M. S. (2009). Construção terminológica e conceitual do controle aversivo: Período Thorndike-Skinner e algumas divergências remanescentes. Temas em Psicologia, 17, 209-224.

Hineline, P. N. (1984). Aversive control: A separate domain? Journal of the Experimental Analysis of Behavior, 42, 495-509. doi: 10.1901/jeab.1984.42-495

Hunziker, M. H. L. (1992). Opioid nature of learned helplessness and stress-induced analgesia without reexposure to shock. Behavioural Pharmacology, 3, 117121.

Iwata, B. A. (2006). On the distinction between positive and negative reinforcement. The Behavior Analyst, 29, 121123. doi: $10.1007 / \mathrm{bf03392123}$

Jwaideh, A. R., \& Mulvaney, D. E. (1976). Punishment of observing by a stimulus associated with the lower of two reinforcement frequencies. Learning and Motivation, 7 , 211-222. doi: 10.1016/0023-9690(76)90029-1

Lattal, K. A., \& Lattal, A. D. (2006). And Yet ...: Further comments on distinguishing positive and negative reinforcement. The Behavior Analyst, 29, 129-134. doi: 10.1007/bf03392125

Marr, M. J. (2006). Through the looking glass: Symmetry in behavioral principles? The Behavior Analyst, 29, 125128. doi: 10.1007/bf03392124

Mayer, P. C. M., \& Gongora, M. A. N. (2011). Duas formulações comportamentais de punição: Definição, explicação e algumas implicações. Acta Comportamentalia, 19, 47-63.

Michael, J. (1975). Positive and negative reinforcement, a distinction that is no longer necessary; or a better way to talk about bad things. Behaviorism, 3, 33-44. 
Michael, J. (2006). Comment on Baron and Galizio (2005). The BehaviorAnalyst, 29, 117-119. doi: $10.1007 /$ bf03392122

Nakajima, S. (2006). Speculation and explicit identification as explicit standards for positive and negative reinforcement: A comment on Baron and Galizio (2005). The Behavior Analyst, 29, 269-270. doi: $10.1007 / \mathrm{bf03392135}$

Palermo-Neto, J. (2006). Effects of physical and psychological stressors on behavior, neurochemistry and innate immunity. Physiological Mini-Reviews, 2, 15.

Perone, M. (2003). Negative effects of positive reinforcement. The Behavior Analyst, 26 (1), 1-14. doi: 10.1007/bf03392064

Santos, G. C. V., \& Hunziker, M. H. L. (2010). Relação entre controle aversivo e variabilidade comportamental: Análise geral e um estudo preliminar. In E. Cillo, M. R. Garcia, P. Abreu \& P. Faleiros (Eds.), Sobre comportamento e cognição: Vol 23 (pp. 303-312). Santo André, SP: ESETec.

Sidman, M. (2006). The distinction between positive and negative reinforcement: Some additional considerations. The Behavior Analyst, 29, 135-139. doi: 10.1007/bf03392126

Skinner, B. F. (1953). Science and human behavior. New York, NY: Free Press.

Skinner, B. F. (1957). Verbal behavior. New York, NY: Appleton-Century-Crofts.

Skinner, B. F. (1974). About behaviorism. New York, NY: Alfred A. Knopf.

Staats, A. W. (2006). Positive and negative reinforcers: How about the second and third functions? The Behavior Analyst, 29, 271-271. doi: 10.1007/bf03392136

Watson, J. B. (1913). Psychology as the behaviorist views it. Psychological review, 20, 158-177. doi: 10.1037/h0074428
White, P. A. (2009). Not by contingency: Some arguments about the fundamentals of human causal learning. Thinking \& Reasoning, 15, 129-166. doi: 10.1080/13546780902734236

Submetido em: 14/03/2019 Aceito em: 27/06/2019 